\title{
THE VALUE-ADDED MARKETING - LOCAL PRODUCTS IN CONFORMITY WITH VITAL RURAL AREAS
}

\author{
Y. Dzhabarova ${ }^{1 *}$, M. Peneva ${ }^{2}$ \\ ${ }^{1}$ Department of Marketing and International Economic Relations, Plovdiv University "Paisii \\ Hilendarski", Plovdiv, Bulgaria \\ ${ }^{2}$ Department of Natural Resources Economics, University of National and World Economy (UNWE), \\ Sofia, Bulgaria
}

\begin{abstract}
In the recent years farmers has begun to search for additional on-farm activities in order to satisfy consumers' needs and preferences, and to increase their incomes as well. During that time many alternative forms of tourism have appeared and developed, such as rural tourism, agritourism, cultural tourism, etc. In this regard, the food is supposed to play an essential role in bridging agriculture and tourism, and consequently to reveal an opportunity for SMEs to develop the existing niche market, and to enhance sustainability and vitality of local areas. The survey is a part of FP7 Project, entitled "Farming transitions: Pathways towards regional sustainability of agriculture in Europe" (FarmPath), carried out on the area of the Municipality of Elena, located in the Central-north part of Bulgaria. This region is typical with its unique local resources, combining the tourism advantages, local people, and the traditions in agriculture, food and culinary as well. This case study aims at introducing and disseminating "a new form of local governance", which will bring some form of health or ethical benefits both for the consumers and the community as a whole, and will promote the people, places, best farming practices, and the cuisine in the area. The value-added products are considered as an essential and adequate marketing tool in order to achieve this synergy effect and the already set up purpose.
\end{abstract}

Key words: marketing, value-added products, tourism, local sustainable development

\section{INTRODUCTION}

In Europe the development of rural and agritourism concept dates back to $1950 \mathrm{~s}$, as many people have preferred to spend their holidays close to the nature, to the beautiful landscape and rural lifestyle. Usually it has started as tourism on farm with the associated farm activities. Over the years, rural tourism has been expanded and diversified its activities, like cultural and leisure activities (hiking itineraries, target guided tours, mountain biking, horse riding, extreme climbing and sports, preparing and sale of farm products, local traditional cuisine, activities for children etc.).

In Bulgaria the rural tourism has arisen in early 90 s and "matured" in the mid of 90s, when many mountainous and semi-mountainous rural areas has begun to offer services in rural

\footnotetext{
*Correspondence to: Yulia Dzhabarova", Plovdiv University "Paisii Hilendarski", Department of Marketing and International Economic Relations, 24 Tzar Assen str., Plovdiv 4000, Bulgaria, j_jabarova@yahoo.com
}

tourism. The change of the economic model from centrally planned to market economy has led to many economic and social changes, such as: closure of many state industrial enterprises, growing unemployment, etc. Additionally, the demographic changes in the country as deterioration of the population age structure, followed by migration (especially of the active population and young people), have been also factors that affected the quality of life and available human capital. At the same time the people's deploying initiative and entrepreneurship have appeared, giving them the opportunity to start a business or undertaking. Alternative forms of tourism have emerged as a prerequisite to diversify the tourist product, local activities, and incomes. They have appeared to be a future stable perspective for local people and economies.

The paper explores the possibility to develop "a new form of local governance" on the territory of the Municipality of Elena. It could be determined by two sub-initiatives, i.e. development of rural and agritourism on one 
side, and traditional agriculture and food production on the other side. The new form of governance is based on the idea to integrate the two sub-regimes - tourism and agriculture in order to attain joint development, interaction and support between them. The main aim is to achieve a synergy effect, resulting in the development of an integrated product of rural tourism and traditional agriculture, which will ensure sustainable development of the whole municipality as an economic region and territory. The value-added products are proposed to be a core unit in this interaction due to their unique characteristics and advantages. The benefit comes from the performed concomitant value-added activity. Another distinction is that the value-added returns directly to the producers, excluding agribusiness processors. In this regard, the value-added developments will help to support and sustain local agriculture. (1)

\section{MATERIALS AND METHODS}

The survey is based on the case-study approach, provided via the frame of FP7 project, entitled "Farming transitions: Pathways towards regional sustainability of agriculture in Europe" (FarmPath). (2)

A multi-step approach is applied in the empirical research. The method of semistructured interviews is used to collect primary information. The thematic sections in the questionnaires aim at extracting valuable expert information from different representatives in the region. Field observations are carried out in order to obtain a various information about different regional characteristics, and to enrich the data from the inquiry as well.

\section{Definition setting}

According to the definition of the U.S.D.A. (3) the value-added products are defined as follows:

- A change in the physical state or form of the product (such as milling wheat into flour or making strawberries into jam).

- A production of a product in a manner that enhances its value, as demonstrated through a business plan (such as organically produced products).

- A physical segregation of an agricultural commodity or product in a manner that results in the enhancement of the value of that commodity or product (such as an identity preserved marketing system).

As a result of the change in the physical state or the manner in which the agricultural commodity or product is produced and segregated, the customer base is expanded and a greater portion of revenue derived from the marketing, processing or physical segregation is made available to the producer of the commodity or product.

\section{DISCUSSION}

\section{The legal framework - the EU defense of variable and high-quality products}

The EU CAP, respectively RDP 2014-2020 (4), strongly influences the farmers - through measures and mechanisms of regulation, and drives them to produce higher quality, competitive, and environmentally friendly agriproducts.

The set up regulations within the Quality policy of the EU aimed at encouraging and protecting the production of traditional specialty guaranteed products/food with geographical origin of a small geographical area. The positive impact on the area, both at regional (district) and municipal level is a crucial point in the policy, as the protection and certification gives local producers incentives to take advantage of EU measures to protect value-added products, to guarantee their quality and uniqueness, and mostly to expand their market opportunities. In the Municipality of Elena runs preparation for application to protect "Elenski but" (Elena ground) and the organic honey as traditional specialty products.

\section{Regional characteristics}

Municipality of Elena (LAU 1 level) is located in Central Northen Bulgaria. It consists of Elena town and 123 villages. The total territory of the municipality is 671,39 sq. $\mathrm{km}$., as $55,8 \%$ are forests and 38,9\% - agricultural land. It is a semi-mountainous region with altitude ranging from $100 \mathrm{~m}$ to $1536 \mathrm{~m}$. (Municipality plan for development of the Municipality of Elena, 2014) (5)

The total population of the municipality is around 9250 people (6), which comprises $3,6 \%$ of the population of the Veliko Tarnovo District, and more than half of which $(59,4 \%)$ live in the municipality centre - Elena town. For the period 2008-2012 the municipality population decreases with $12 \%$. The population density is also very low $-13,8$ inhabitants per sq.km. There are settlements, mainly in the mountains, with population less than 20 people, as most of them are over the retirement age. For the last ten years nine villages were depopulated. About $23 \%$ of the municipality population is presented by ethnic minorities, which are concentrated in a few villages. The infrastructure conditions 
negatively affect the quality of life in the area, and particularly in the settlements, situated at a large distance from the administrative centre.

The Municipality of Elena is located in an industrial-agrarian region, and the economic structure is predominantly presented by the processing industry (70\% of the produce), followed by the agricultural production $(7 \%)$, and trade (6\%) (5). In the recent years there is a stable growth of the sector of services. New small and medium enterprises, mostly private, have restored the traditional business and currently successfully operate in the field of timber and clothing industry, wood-processing, tailor enterprises, processing of wild fruits and herbs, and different services (hotels and restaurants, tourism facilities, etc.) as well.

The farm structure on the territory of the municipality is determined by the terrain and natural conditions. The vast majority of the farm holdings in the region are presented by holdings of medium- and small-sized farms. There is only one agricultural cooperative and a few larger land leasers.

The livestock breeding is concentrated in small farms, specialised in pig-breeding, sheep- and goat-breeding, and cattle-breeding. The crop production is carried out mainly by the cooperative and 2-3 leaseholders, cultivating from 20 to 50 ha land, and another one cultivating 100 ha.

Local people produce agricultural products, predominantly for their own consumption, using own fields and gardens. Some of them sell a part of the produce and operate as semisubsistence farms, mainly in vegetable and meat production, bee-keeping (organic beekeeping), etc.

Some of the guest houses also produce vegetables and other home-grown products but it is only for the use of their visitors and their needs.

In the last years a number of changes have been occurred in the agriculture profile:

- Areas planted with permanent crops (plums, cherries, raspberry, currant, aronia and strawberries) have been reconstructed and increased.

- Livestock breeding (pig-breeding, sheep and goat-breeding, and cattle-breeding) has been provided on small farms. Breeding and preservation of local sheep breeds have been carried out.

- Organic bee-keeping has appearing.

- Cultivation and collection of wild herbs and mushrooms have been developed.
- Vegetable-growing, which was a traditional sector in the past, now it has been restored.

In technological terms, the transition can be seen in the change of agricultural practices and the methods of crop cultivation and animal breeding. Emergent transition is observed in the already initiated organic bee-keeping and organic aronia selection and growing, aronia and wine producing, cultivation of a big variety of (wild) herbs and species. Using modern processing technologies, a new enterprise in collecting and packaging herbs and mushrooms has been established.

\section{Local products - a source to revive local traditions - based on the best practices in the region}

The traditional food production in the municipality aims to apply for the local certification scheme in order to popularize local food specialities and promote the Municipality of Elena as a preferred place for rural tourism.

Some of the well-known traditional food specialties are: "Elenski but" (Elena ground), prepared due to the specific climate of Elena area; fillet Elena (7), which is a pressed rawdried meat product prepared from fresh pork loin and natural spices; Elena plum brandy; organic Balkan honey; aronia wine; milk and dairy products from the region; herbs (common balm, stevia, etc.).

"Elena" milk processing company produces a big range of milk and dairy products (feta cheese and white cheese, various kinds of fruit yogurts, etc.).

The local vegetable growing sector is also offering local products to the local restaurants and traditional food shops. Their main clients are Bulgarian and foreign tourists.

\section{Interactions within the "new form of local governance"}

Considering the regional specifics in the context of sustainable development of the Municipality of Elena, and applying the concept of integration of the two sub-regimes tourism and agriculture, in order to attain common development and support between them, the following interactions of the "new form of local governance" can be drawn:

\section{A. Policy measures}

Policy measures that are undertaken and sustain the presented initiative are: the rural development program, tourism legislation, adoption of the regulation for direct sales of agricultural products, implementation of the 
EU policy for geographical indications, designations of origin and traditional specialities guaranteed for agricultural products and foodstuffs.

\section{B. Market processes}

- The market processes are sustained by different market activities, such as: the implemented direct sales mainly of honey and other agricultural products; the developed common labelling, offered by the Association of the local bee-keepers; the specialized shop in the town of Elena, operating only with local food and food stuffs; the improved tourist product, as hotel-keepers start to offer complex services and improvements in the staff qualification, etc.

- We ascertain that there is unequal distribution of value added across the agrifood system - local small and medium sized producers are "at the bottom" of the local agrifood system. They do not have the power to change the market situation and the existing agrifood system, due to the: (1) inconsistency/instability of their production; (2) dependency from the bigger market players on the agricultural products market, who have the power to influence the price level and the role of the different actors. There is a food-delivery chain, as producers - processors - intermediaries food retail chains, established and operating as a big market player and competitor as well, which prevents the small local producers from entering the free market place.

- Consumer preferences seem to be the main driver of the changes in hotel facilities, products and services offered. The increased consumers' awareness and their interest in environmentally friendly products, recreational places and nature activities, lead to the increased demand for such products and services. Even more, consumers' preferences and their behavioural changes force the process of strengthening the interactions between producers, processors and consumers. The increased consumer demand leads to diversifying and enriching the tourist product and its transformation into an integrated tourist product with the label "Elena" like: accommodation - local food entertainment - exploratory activities tourism and recreation.

\section{The tourist product performance}

- A big variety of the accommodation establishments exists. According to the municipality expert in "Trade and tourism", officially registered places consist of hotels, guest houses, separated rooms, family hotels, small hotels, bungalows, etc. "There is no settlement without at least one accommodation establishment, as the municipality consists of 124 settlements." At the same time, the farmers' intention to start offering tourist services (accommodation, food and entertainments) is increasing.

- There is a tendency of commercialization of the tourist product according to the key informants' opinion. The main characteristics of that process are: obtaining higher income through unduly increased prices, offering meals at the same price but in lower quantity, offering just the main services as "food and accommodation", etc. In other words, there is a tendency to routine the activities and services offered as a part of the rural tourist product which is inconsistent in its nature.

- Most of the guest houses and hotels are situated in the town. They are partially developed hotel complexes consisting of a hotel part, restaurant, animations and other tourism facilities. All tourist establishments and attractions within agriculture and natural resources are spread all over the municipality.

\section{Social activities and events}

- There is a big variety of social events, such as: organised community fests, sport events, organised public discussion on the Municipality Development Plan, and on the elaboration of the Local Development Strategies (LDS) of the Local Action Groups (LAG).

There are several regional fests, sport and social events which stimulate the contacts between local people, and strengthen cultural and cognitive tourism as well. Some of the events are:

- The Elena town festival - yearly organized in the days around 21 May, with many exhibitions, concerts, football matches, children programs, etc.

- The festival, named "Balkan sings and tells tales" - organised in June. It is a celebration of the traditional folk music and dances, which comes from the region of the Balkan mountain.

- The march to Kapinovski Monastery organized every year in July, when the three rays: pedestrian, cycle and auto-march meet together at the monastery.

- The activities of the Tourist Society "Chumerna" and the Sports Society "Chumerna" support the reconstruction and renovation, and also the enhancement and modernization of the technical sport 
equipment and the infrastructure in the region. Thus they offer a new variety of attractions to supplement the tourist product of the Municipality of Elena, such as: guided tours to the natural, cultural and historical places, marches along the tourist routes and trails, unconventional sports (orienteering and bicycling) and extreme sports (rock climbing and indoor artificial rock climbing wall) and many others.

- The interaction between municipality authorities and local people is strengthened by the implementation of the project "Development of partnership between citizens and local authorities in the municipality of Elena" in 2001-2004, financed by the Irish Government and Norway. The project encouraged citizens' initiatives and strengthened the civil participation in the local government.

\section{CONCLUSION}

The development and implication of the "new form of local governance" on the territory of the Municipality of Elena gives the following outcomes and set up a solid base to disseminate the value-added marketing approach:

- Promoting and strengthening the position of the Municipality of Elena as a destination for alternative tourism.

- Diversification of farmers' activities with developing and promoting tourist services and products. This initiative results in diversified higher incomes.

- Revival of the image of local production and traditions as the tourist places start to offer local products and cuisine, delivering valueadded products to tourists.

- The local food specialities like Elena round gain a higher popularity as some of the hoteliers produce and offer them to the tourists.

- Strengthening the local brand "Elena" through different products and promotional activities, forming an identity-preserved marketing system.

- Agricultural activities are carried out according to the best agricultural practices that perform the multifunctional role of agriculture.

- Development of new tourist attractions mountain biking, rock climbing, rope trolley, swimming pools, zoos, horseback riding, visiting a farm (though sporadic), eco-paths, visits to apiaries, various games such as paint ball, tennis, hunting, etc.

This sustainable local framework could serve as a pattern, and a proved perspective for many other similar municipalities and regions. On this basis they could design their own model for "new form of local governance". Valueadded marketing can be an important component of the "new form of local governance", and a future option for viable businesses, which will depend on the involvement and commitment of farmers and rural residents.

\section{REFERENCES}

1. Ellerman, J., Value Added Opportunities for Agriculture - Wave into the Future, Farm Management Update, Ohio State University Extension, Spring 2003. (available at: http://ohioline.osu.edu/fmnews/sp03/sp03.pdf)

2. Draganova, M., Peneva, M., Kazakova, Y., Mishev, P., Rural Development Based on Sustainable Tourism and Local Food Production: The Municipality of Elena (Bulgaria), FarmPath Working Report, 2012.

3. http://www.agmrc.org/business_developme nt/getting_prepared/valueadded_agriculture /articles/usda-value-added-ag-definition/

4. http://www.dfz.bg/bg/prsr-2014-2020/

5. elena.acstre.com/assets/Novini/2014/5/27/O PR_Elena_2020_23May14_final.pdf

6. www.nsi.bg

7. http://meattradition.bg/files/download/docs/ $\% \mathrm{D} 0 \% 97 \% \mathrm{D} 0 \% \mathrm{~B} 0 \% \mathrm{D} 1 \% 8 \mathrm{~F} \% \mathrm{D} 0 \% \mathrm{~B} 2 \% \mathrm{D}$ 0\%BB\%D0\%B5\%D0\%BD\%D0\%B8\%D0 $\%$ B5\%20\%D1\%81\%D0\%BF\%D0\%B5\%D 1\%86\%D0\%B8\%D1\%84\%D0\%B8\%D0\% BA\%D0\%B0\%D1\%86\%D0\%B8\%D1\%8F $\% 20 \% \mathrm{D} 0 \% \mathrm{~B} 7 \% \mathrm{D} 0 \% \mathrm{~B} 0 \% 20 \% \mathrm{D} 1 \% 80 \% \mathrm{D}$ 0\%B5\%D0\%B3\%D0\%B8\%D1\%81\%D1\% 82\%D1\%80\%D0\%B0\%D1\%86\%D0\%B8 $\% \mathrm{D} 1 \% 8 \mathrm{~F} \% 20 \% \mathrm{D} 0 \% \mathrm{BD} \% \mathrm{D} 0 \% \mathrm{~B} 0 \% 20 \% \mathrm{D}$ $0 \% \mathrm{~A} 5 \% \mathrm{D} 0 \% \mathrm{~A} 2 \% \mathrm{D} 0 \% \mathrm{~A} 1 \% \mathrm{D} 0 \% \mathrm{~A} 5 \% 20 \%$ D0\%A4\%D0\%B8\%D0\%BB\%D0\%B5\%20 $\% \mathrm{D} 0 \% 95 \% \mathrm{D} 0 \% \mathrm{BB} \% \mathrm{D} 0 \% \mathrm{~B} 5 \% \mathrm{D} 0 \% \mathrm{BD} \%$ D0\%B0.pdf 